\title{
Fronteira Etnocultural entre Kadiwéu e Terena: A Representação Social da Educação Ambiental dos Povos Indígenas da Região do Pantanal Sul
}

\author{
Frontera Etnocultural entre Kadiwéu y Terena: La Representación Social \\ de la Educación Ambiental de los Pueblos Indígenas de la Región del \\ Pantanal Sur
}

Ethnocultural Frontier between Kadiwéu and Terena: The Social Representation of Environmental Education of the Indigenous Peoples of the South Pantanal Region

\author{
Edson Pereira de Souza ${ }^{1}$ \\ Antonio Hilário Aguilera Urquiza \\ Victor Ferri Mauro 3 \\ Icléia Albuquerque de $\operatorname{Vargas}^{4}$
}

\begin{abstract}
Resumo
No Brasil, literaturas e mídias denunciam ameaças à biodiversidade, decorrentes, sobretudo, pelo desenvolvimento populacional (desordenado) e pelas atividades produtivas sem estudos prévios. Tais situações geram danos ambientais nos biomas, como a deterioração do solo, o assoreamento, a contaminação dos corpos d'água, o desmatamento e outros, somados aos efeitos provocados pela exclusão social e índice de pobreza das populações indígenas, os quais interferem na produção de conhecimentos de tais grupos sociais. Considerando essa realidade, desenvolveu-se este trabalho em duas escolas distintas, com etnias Kadiwéu e Terena como predominantes, foi definido o seguinte problema de pesquisa: como a Educação Ambiental, a partir das territorialidades indígenas, configura-se por meio das representações sociais para as etnias Kadiwéu e Terena na região do Pantanal Sul? Estabeleceu-se, portanto, como objetivo geral, compreender a interface entre os grupos étnicos Kadiwéu e Terena, relacionados à(s) territorialidade(s) de representação(ões) social(is) sobre Educação Ambiental na Região do Pantanal Sul. Metodologicamente, trata-se de uma pesquisa de abordagem qualitativa, de cunho exploratório, longitudinal, caracterizando-se como um estudo de caso etnográfico. No entanto, a partir das territorialidades evidenciadas nas representações sociais, se percebe a existência da fronteira etnocultural. Acredita-se, então, que os saberes tradicionais possam promover o uso sustentável e a manutenção de boas práticas de Educação Ambiental. Ademais, esses saberes tradicionais devem, também, ser considerados nos momentos empíricos relativos à Educação Ambiental na comunidade. Afinal, ao se buscar os conhecimentos com ferramentas geo-pedagógicas, torna-se possível contribuir para o processo educativo, utilizando práticas e reflexões em Educação Ambiental.
\end{abstract}

\footnotetext{
${ }^{1}$ Doutorando em Ensino de Ciências; Programa de Pós-Graduação em Ensino de Ciências - PPEC; Campo Grande, Mato Grosso do Sul, Brasil; edson.souza1984@gmail.com

${ }^{2}$ Doutor; Programa de Pós-Graduação em Antropologia Social - PPGAS; Campo Grande, Mato Grosso do Sul, Brasil; hilarioaguilera@gmail.com

${ }^{3}$ Doutor; Programa de Pós-Graduação em Antropologia Social - PPGAS; Campo Grande, Mato Grosso do Sul, Brasil; victorfmauro@gmail.com

${ }^{4}$ Doutora; Programa de Pós-Graduação em Ensino de Ciências - PPEC; Campo Grande, Mato Grosso do Sul, Brasil; icleiavargas12@gmail.com
} 
Palavras-Chave: Educação Ambiental; Fronteira Etnocultural; Pantanal Sul; Povos Indígenas; Representação Social.

\title{
Resumen
}

En Brasil, literaturas y medios denuncian amenazas a la biodiversidad, derivadas, sobre todo, por el desarrollo poblacional (desordenado) y por las actividades productivas sin estudios previos. Estas situaciones generan daños ambientales en los biomas, como el deterioro del suelo, el asentamiento, la contaminación de los cuerpos de agua, la deforestación y otros, sumados a los efectos provocados por la exclusión social y el índice de pobreza de las poblaciones indígenas, que interfieren en la producción de conocimientos de tales grupos sociales. En este sentido, se desarrolló este trabajo en dos escuelas distintas, con etnias Kadiwéu y Terena como predominantes, se definió el siguiente problema de investigación: como la Educación Ambiental, a partir de las territorialidades indígenas, se configura por medio de las representaciones sociales para las etnias Kadiwéu y Terena en la región del Pantanal Sur? Se estableció, por lo tanto, como objetivo general, comprender la interfaz entre los grupos étnicos Kadiwéu y Terena, relacionados a la (s) territorialidad (s) de representación (es) social (es) sobre Educación Ambiental en la Región del Pantanal Sur. Metodológicamente, se trata de una investigación de abordaje cualitativo, de cuño exploratorio, longitudinal, caracterizándose como un estudio de caso etnográfico. Sin embargo, a partir de las territorialidades evidenciadas en las representaciones sociales, se percibe la existencia de la frontera etnocultural. Se cree, entonces, que los saberes tradicionales puedan promover el uso sostenible y el mantenimiento de buenas prácticas de Educación Ambiental. Además, estos saberes tradicionales deben, también, ser considerados en los momentos empíricos relativos a la Educación Ambiental en la comunidad. Al final, al buscar los conocimientos con herramientas geo-pedagógicas, se hace posible contribuir al proceso educativo, utilizando prácticas y reflexiones en Educación Ambiental.

Palabras claves: Educación ambiental; Frontera Etnocultural; Pantanal Sur; Pueblos Indígenas; Representación Social.

\begin{abstract}
In Brazil, literature and media denounce threats to biodiversity, mainly due to population (disorderly) development and productive activities without previous studies. Such situations generate environmental damages in the biomes, such as soil deterioration, silting, contamination of water bodies, deforestation and others, together with the effects caused by social exclusion and poverty index of indigenous populations, which interfere in the production knowledge of such social groups. Considering this reality, this work was developed in two distinct schools, with Kadiwéu and Terena ethnicities as predominant, the following research problem was defined: how the Environmental Education, from the indigenous territorialities, is configured through the social representations for the Kadiwéu and Terena ethnic groups in the Pantanal Sul region? It was therefore established as a general objective to understand the interface between the Kadiwéu and Terena ethnic groups related to the territoriality (s) of social representation (s) on Environmental Education in the Pantanal Sul Region. Methodologically, it is a research of qualitative, exploratory, longitudinal approach, characterizing itself as an ethnographic case study. However, from the territorialities evidenced in the social representations, one can perceive the existence of the ethnocultural frontier. It is believed, then, that traditional knowledge can promote the sustainable use and maintenance of good Environmental Education practices. In addition, these traditional knowledge should also be considered in the empirical moments related to Environmental Education in the community. After all, when seeking knowledge with geo-pedagogical tools, it becomes possible to contribute to the educational process, using practices and reflections in Environmental Education.
\end{abstract}

Keywords: Environmental education; Ethnocultural Frontier; Pantanal Sul; Indian people; Social Representation.

\section{Introdução}

Pela ótica intelectual contemporânea há a expressiva difusão da tradição de pensamento a qual ataca as aspirações objetivistas científicas e que reconhece um elo entre o conhecimento científico e o respectivo controle ou domínio de algo o qual se passou a compreender (SALVI E BATISTA, 2007). 
Logo, quando se propõe a desenvolver atividades de pesquisa junto aos povos indígenas, é necessário evidenciar a empiricidade, ora, reporta-se a Lacey (1998) que auxilia a identificar e ver um valor neste sistema social: o desenvolvimento de práticas de controle e conservação dos recursos dados pela natureza.

Já anunciava Comte, ainda no século XIX que, um sistema social está sempre em constante metamorfose. Comte (s/d, p.13) chama de reorganização, onde esta é "[...] conduzida para o estado social definitivo da espécie humana, aquele que mais convém a sua natureza, aquele em que todos os seus meios de propriedade devem merecer o mais amplo desenvolvimento e sua aplicação mais direta".

Nessa multiplicidade de se buscar condicionantes para reorganizar a sociedade, a partir de uma perspectiva de desenvolvimento, entendendo este como equilíbrio de relações entre a sociedade-natureza, aborda-se neste artigo as relações dos povos indígenas com o ambiente natural, configurando-se numa relação de fronteira etnocultural.

Essa fronteira etnocultural emana dos contatos, nas relações e embates entre grupos culturalmente distintos, transcendendo os limites territoriais (SOUZA, 2012). Nesse contexto, embasa-se esta fronteira etnocultural a partir de quatro elementos: fronteira; etnicidade; território e territorialidade. Contudo, neste artigo, foca-se no elemento territorialidade visando a configuração das representações sociais sobre educação ambiental dentre os povos indígenas.

Logo, delimitou-se como loci de pesquisa a Escola Evangélica Lourenço Buckman e a Escola Municipal Indígena Ejiwajegi. Aquela, liderada por irmãs, no sentindo de parentesco, indígenas Terena, situada no Distrito de Taunay, pertencente ao município de Aquidauana (MS), na região do Pantanal Sul, é uma das poucas que recebem diferentes etnias no mesmo território educacional: "Cinta Larga, Guarani, Kadiwéu, Kaiowa, Kinikinawa" (SOUZA, 2012, p.46), e também Xavante, oriundos de Mato Grosso, porém o predomínio é Terena. A outra escola, situada na Reserva Indígena Alves de Barros, pertencente ao município de Porto Murtinho-MS, na região do Pantanal Sul, é a única escola da região e somente recebe alunos da etnia Kadiwéu.

Esta pesquisa buscará responder o seguinte problema de investigação: Como a educação ambiental, a partir das territorialidades indígenas, se configura nas representações sociais desses grupos entre as etnias Kadiwéu e Terena na região do Pantanal Sul? Mediante esta problemática proposta, definiu-se o objetivo geral em compreender a interface entre os grupos étnicos Kadiwéu e Terena relacionados com a(s) territorialidade(s) de representação(ões) social(is) sobre educação ambiental na Região do Pantanal Sul.

Para tanto, metodologicamente, desenvolveu-se esta pesquisa a partir de métodos científicos, com abordagem na pesquisa qualitativa que conforme Chizzotti (2008, p.28) visa "extrair do convívio os significados visíveis e latentes que somente são perceptíveis a uma atenção sensível”. Logo, a pesquisa qualitativa, permite-nos ter uma percepção de premissas quanto à dinâmica entre a realidade e o sujeito.

Ora, percebe-se em Silva e Menezes (2005, p.20) uma "indissociabilidade entre a forma de vida objetiva e a subjetividade dos atores sociais que, às vezes, não se traduz numericamente", como é o caso da pesquisa quantitativa, ressalta-se que não foram necessários usos de métodos e técnicas de cunho estatístico, justamente para não se limitar na coleta das informações. 
Além disso, esta pesquisa configura-se de forma exploratória (buscando familiaridade com o local e temática, ambos pouco explorados), longitudinal (em decorrência da temporalidade/convívio com o local de pesquisa ${ }^{5}$ ), e caracterizando-se em um estudo de caso etnográfico (buscando reunir informações detalhadas e sistemáticas sobre a cultura e o comportamento de grupos sociais indígenas das etnias Kadiwéu e Terena).

Durante as investigações iniciais ocorreram trocas de saberes entre sujeitos pesquisadores e pesquisados nas escolas citadas, além do desenvolvimento de atividades geopedagógicas ${ }^{6}$ sobre Educação Ambiental. Logo, este contato e vivência permitiram-nos, mediante um olhar externo, buscar compreender a amplitude das territorialidades a partir da configuração de representação social dos povos indígenas sobre a Educação Ambiental, como reposicionamento do ser por meio do saber (LEFF, 2006).

O embasamento teórico, para este trabalho foi pautado em Jodelet (1989); Moscovici (1978); Poutignat e Streiff-Fenart (1998); Raffestin (1993); Machado (1998); Sack (1986); Bourdieu (2010); Souza (2012); e Guerra, Enedino e Nolasco (2012). Foram desenvolvidas técnicas de observação sistemática da realidade local, utilizando-se como principais instrumentos de registro da pesquisa de campo a caderneta de campo e a câmera fotográfica.

Foi realizada uma capacitação nas escolas indígenas envolvendo 7 (sete) professores Kadiwéu e 13 (treze) professores Terena. Desenvolveram-se técnicas geo-pedagógicas voltadas para a Educação Ambiental, partindo de territorialidades dos saberes tradicionais, visando verificar como essas territorialidades são expressas nas representações sociais.

Sêga (2000, p.128) esclarece que "a representação que um grupo elabora sobre o que deve fazer para criar uma rede de relações entre seus componentes faz com que defina os mesmos objetivos e procedimentos específicos", ora, descobre-se a indução social da coletividade.

Contudo, observa-se que as representações sociais "[...] se apresentam como uma maneira de interpretar e pensar a realidade cotidiana (SÊGA, 2000, p.128)". Enxerga-se, com isso, uma possibilidade de conhecimento da atividade mental desenvolvida pelos indivíduos e pelos grupos para fixar suas nuances etnoculturais. Entretanto, foi possível perceber que os professores indígenas têm interesse em conhecer novas práticas geo-pedagógicas voltadas para a Educação Ambiental, expressadas na linguagem e símbolos (BOURDIEU, 2010).

Este artigo foi sistematizado em duas partes, na primeira se buscará contextualizar a fronteira etnocultural para a prática de educação ambiental nas escolas indígenas, a partir da identificação de características quanto a representação social; na segunda parte se apresentará a importância da língua materna como elemento base para a representação social na compreensão sobre Educação Ambiental para os povos indígenas, sobretudo dentre os Kadiwéu e Terena.

\footnotetext{
${ }^{5}$ Atuação em terras indígenas de 2005 até os dias atuais.

${ }^{6}$ São atividades pedagógicas embasadas no contexto teórico-metodológico da geografia.
} 
Portanto, percebe-se no decorrer deste trabalho que a fronteira etnocultural pôde ser comprovada pela especial interação entre indígenas e não indígenas, e que a preocupação de manutenção da língua materna, enquanto elemento da cultura e territorialidade de representação social é evidente para a construção e compreensão do conhecimento sobre educação ambiental.

\section{CONTEXTUALIZAÇÃO SOBRE FRONTEIRA ETNOCULTURAL PARA A PRÁTICA DE EDUCAÇÃO AMBIENTAL NAS ESCOLAS INDÍGENAS}

Geograficamente, a fronteira etnocultural emerge nos contatos e embates entre grupos étnicos distintos, que por sua vez transcende os limites territoriais (SOUZA, 2012). Imersos nessa realidade é que se busca neste capítulo a contextualização sobre a fronteira etnocultural voltada para o desenvolvimento de práticas geo-pedagógicas em Educação Ambiental nas escolas indígenas apresentadas.

Porém, inicia-se com uma contextualização geo-histórica, destacando que os povos indígenas do Brasil compreendem um elevado número de diferentes grupos étnicos que habitam o país antes do início da colonização europeia. No momento da chegada dos europeus ao Brasil, os povos ameríndios eram em grande parte, compostos por grupos seminômades, que subsistiam da caça, pesca, coleta e da agricultura itinerante.

Muitos dos povos existentes no território brasileiro no século XVI foram exterminados em consequência de processos de dominação (exploração, escravização, perdas territoriais) e doenças desencadeados pelos colonizadores. Os sobreviventes e resistentes passaram a sofrer o impacto da persistente tentativa do Estado em integrá-los e assimilá-los à sociedade nacional, como cidadãos brasileiros, ou melhor, como reserva de mão de obra no projeto de colonização.

Apesar desse processo histórico de negação da diversidade étnica e cultural, mais de 300 (trezentos) indígenas sobreviveram e atualmente estão espalhados em território nacional, cada qual com suas especificidades.

Por outro lado, pouco se sabe sobre a natureza e motivos que animam as estratégias das representações sociais a partir dos saberes tradicionais na região do Pantanal Sul, tampouco sobre as relações das práticas que possam ser caracterizadas como Educação Ambiental e de interdependência que afetam e redefinem a existência desta fronteira etnocultural. Sobretudo, tal conceito, ainda em construção, refere-se à complexidade das relações sociopolíticas em territórios questionados e mesmo indefinidos quando na existência de práticas voltadas à educação ambiental.

De acordo com o Art. $3^{\circ}$ da Constituição Federal de 1988, constituem-se como objetivos fundamentais da República: construir uma sociedade livre, justa e solidária; garantir o desenvolvimento nacional; erradicar a pobreza e a marginalização e reduzir as desigualdades sociais e regionais; promover o bem de todos, sem preconceitos de origem, raça, sexo, cor, idade e quaisquer outras formas de discriminação. 
Desse modo, a Educação Ambiental apresenta-se como um modo de analisar a função do ser humano no mundo, buscando promover e difundir posturas participativas e integracionistas, em que cada indivíduo envolvido seja estimulado e possa exercer plenamente sua cidadania, revelando um despertar mais solidário e humanitário para as práticas socioambientais.

Todavia, os povos tradicionais se apresentam mais conectados à natureza. $\mathrm{O}$ Cerrado $\mathrm{e}$ o Pantanal, biomas nos quais se encontram as escolas analisadas, constituem-se em elementos fundamentais para a manutenção e permanência da vida das comunidades tradicionais indígenas as quais habitam a região e usufruem de seus recursos.

A Educação Ambiental, por sua vez, apresenta-se eficaz no processo de assimilação das relações sociedade e natureza. Esse processo, longo e intensivo, pretende agir no redirecionamento das atividades da população por meio do reconhecimento dos valores ecológicos na definição de qualidade de vida humana, indicando a necessidade de se estabelecer modelos de desenvolvimento socioeconômico compatíveis com a conservação do meio.

Souza et. al (2008, p.01) enfatizam a contribuição do conceito de paisagem pelo entendimento sobre a relação sociedade e natureza, buscando reconhecer que:

[...] a degradação ambiental tem assumido proporções globais em decorrência, principalmente, da crescente evolução tecnológica e do fenômeno da globalização. Impõe-se a necessidade de repensar continuamente a relação ser humano/natureza, no intuito de resgatar e resguardar qualidade de vida aliada a um ambiente sadio.

Além de agregar diferentes dimensões, como: social, política, econômica, cultural e histórica, a educação ambiental se propõe a clarear e reforçar as relações de interdependência entre os seres humanos e o meio ambiente, a valorizar a atitude cidadã e a vivenciar a holisticidade, com o intuito de existirem sujeitos corresponsáveis e proativos na construção de um mundo com melhor qualidade de vida para todos os seres vivos. Para tanto, faz-se imprescindível proporcionar o acesso à informação e, especialmente, oportunidades para que as pessoas vivenciem tal experiência e, de fato, contribuam na construção desses novos valores, tão almejados.

Com isso, apresenta-se a fronteira etnocultural, assim como, as estratégias quanto às práticas de conservação e Educação Ambiental, expressas nas relações interpessoais e interétnicas, que revelam um dinamismo nas performances etnoculturais existentes. As informações discorridas neste artigo tornam-se relevantes na compreensão dos saberes tradicionais e a forma de sua aplicação em sala de aula, na perspectiva de difusão desses conhecimentos para as futuras gerações.

Os saberes tradicionais dos povos indígenas, tanto Kadiwéu quanto Terena, revelam um processo de cuidado com o meio ambiente. Cuidado que se evidencia a partir das práticas de Educação Ambiental desenvolvidas por esses povos em sala de aula, e dos reflexos de empoderamento dessas terras em áreas rurais, que geram interesses e especulações, já que, conforme Dupas (2008, p.23) "a natureza se converteu num problema ético; tão degradada está por ações humanas que nossa relação com ela transformou-se em questão decisiva”. 
Sendo assim, na compreensão desta fronteira etnocultural, divide-a em dois elementos: fronteira e etnicidade. Logo, identifica-se que há inúmeros tipos de fronteira, os quais têm em comum a ideia de interface territorial. A fronteira emerge nos limites territoriais como fenômeno dinâmico e multidimensional. Portanto, fronteira e limite, ainda que unidos, não são sinônimos. Como esclarece Machado (1998), a fronteira indica uma dinâmica de integração e o limite, de separação. A fronteira surge precisamente na interface dos territórios ou, de acordo com Turner (1993), diante do espaço "livre" a ser territorializado (apropriado, dominado, produzido).

A fronteira é um fenômeno socioespacial sistêmico, observado no contato e nas relações com o "diferente" (diferenças políticas, culturais, de organização do espaço, etc.). Para Nogueira (2007), é a convivência com o "outro", com o diferente, que constitui o "dado primordial da fronteira", uma fonte de referência identitária na construção do lugar. É, pois, da diferença que para Raffestin (1993) a fronteira surge.

Posteriormente reporta-se a Poutignat; Streiff-Fernart (1998, p.250), para quem a etnicidade é entendida por um conjunto temporal e dinâmico de "traços culturais, transmitidos da mesma forma de geração para geração na história do grupo". Logo, a etnicidade se transforma em um princípio de divisão, não necessariamente conflitivo, da vida social, mas "permitindo a interação, por meio das relações sociais entre indígenas e não-indígenas, que de maneira direta e/ou indireta comungam por um interesse qualquer" (SOUZA, 2012, p.29-30).

Nesse contexto, percebem-se na etnicidade os símbolos identitários de cada grupo étnico, proporcionando assim a materialização das representações sociais por meio das territorialidades em construção, e a transposição do - limite cultural promovendo a interação por meio de uma origem comum. Para Guerra; Enedino e Nolasco, (2012, p.43), o "branco desconhece o índio", no sentido e que às vezes convivem, mas não há a preocupação de conhecer, interagir e dialogar. Mediante isso, apresentam-se no capítulo a seguir as representações sociais e a relação com a(s) territorialidades, desses dois grupos indígenas, a partir da educação ambiental.

Portanto, a fronteira etnocultural discutida, vai além da eliminação da diferença. Esta possibilita transpor esse limite cultural, a partir da troca de saberes tradicionais, desde que permitido por um determinado grupo étnico, tornando possível a contextualização e compreensão das práticas ambientais desenvolvidas, nas temporalidades e, dinâmicas destes grupos distintos: Kadiwéu e Terena.

\section{A REPRESENTAÇÃO SOCIAL E A(S) TERRITORIALIDADE(S) NA COMPREENSÃO DA EDUCAÇÃO AMBIENTAL}

Em pleno século XXI, torna-se perceptível a urgência quanto à necessidade de modificar as concepções, promovendo as que resgatem os conceitos os quais defendam o respeito pela vida, primando pelos valores de justiça ambiental, diversidade, equidade e sustentabilidade. Nesse contexto, sintetizam-se os conceitos de representação social, territorialidade e educação ambiental. Posteriormente terá uma interface entre estes conceitos a partir dos resultados encontrados in loco.

Primeiramente, no campo das representações sociais, Jodelet (1989, p.17) assevera que: 
[...] sempre há necessidade de estarmos informados sobre o mundo à nossa volta, Além de nos ajustar a ele, precisamos saber como nos comportar, dominá-lo física ou intelectualmente, identificar e resolver os problemas que se apresentam: é por isso que criamos representações. Frente a esse mundo de objetos, pessoas, acontecimentos ou ideias, não somos (apenas) automatismos, nem estamos isolados num vazio social: partilhamos esse mundo com os outros, que nos servem de apoio, às vezes de forma convergente, outras pelo conflito, para compreendê-lo, administrá-lo ou enfrenta-lo. Eis porque as representações são sociais e tão importante na vida cotidiana (grifo nosso).

A autora apresenta as representações sociais como forma de interpretar e analisar aspectos, tomadas de decisões e posicionamentos, a fim de entender como se dão as relações dessa representação social para as práticas e estratégias de manutenção/preservação da cultura, ainda que com influência do mundo externo. Logo, as representações sociais são atuações dinâmicas caracterizadas pela produção de comportamentos com o meio ambiente.

E Moscovici (1978, p.45) defende que a representação social deve ser firmada "tanto na medida em que ela possui uma contextura psicológica autônoma como na medida em que é própria de nossa sociedade e de nossa cultura" (grifo nosso). Dessa maneira, o autor mostra que a representação social se preocupa com a inter-relação entre o sujeito e objeto e como se dá o processo de construção do conhecimento, ao mesmo tempo individual e coletivo, um conhecimento de senso comum, configurando-se num saber tradicional.

Em seguida, a territorialidade, a partir de Sack (1986), analisa a estratégia utilizada entre grupos étnicos para se apropriar e organizar seus territórios. Entretanto, “[...] a territorialidade é melhor compreendida através das relações sociais e culturais que o grupo mantém [...]" (HOLZER, 1997, p.84), ou seja, percebe-se uma dinâmica estabelecida por meio das relações socioculturais enquanto produtos e estímulos (SOUZA, 2012).

Souza (2012, p.40) informa que a territorialidade: “[...] pode ser uma estratégia espacial para afetar, influenciar, ou controlar recursos e pessoas por controle de área. [...] ligada ao uso da terra [...], a organização espacial, e com o significado que o lugar tem para elas". Com isso, percebe-se a estratégia de se manter e divulgar as peculiaridades da cultura local.

Posteriormente, destaca-se que a educação ambiental propõe o estímulo a um despertar crítico, visando a um resgate da postura ética e transformações das atitudes do ser humano em relação ao meio. Já que se configura como um processo transformador que pode contribuir para a implementação prática e efetiva destes saberes tradicionais usando a Educação Ambiental como uma diretriz, promovendo o despertar do desenvolvimento endógeno por parte das escolas, consequentemente, dos(as) professores(as) os(as) quais tomam parte no processo.

Inclusive, a realidade hoje nos impõe novos dilemas, principalmente quando a destruição da natureza já tem resultado na criação de condições inadequadas para a própria espécie humana. Por isso, mudanças neste cenário implicam na necessidade de estratégia, ferramenta ou instrumento capaz de, senão reverter, frear esse processo: "[...] é onde a Educação Ambiental vem contribuir" (GARZONI E PELLIN, 2010, p.02). 
Além disso, segundo Garzoni e Pellin (2010), a Educação Ambiental, torna-se uma ferramenta de caráter absolutamente transformador, a qual procura modificar as atitudes individuais em relação ao espaço geográfico, resgatando possibilidades de postura ética e uma visão holística, que certamente contribuirão na construção de uma melhor qualidade de vida para os habitantes da região do Pantanal Sul.

Desse modo, apresentam-se a representação social e a(s) territorialidade(s) na compreensão da Educação Ambiental, a partir do resultado da atividade geo-pedagógica desenvolvida neste ano em ambas as escolas. Opta-se por apresentar os resultados de maior relevância e representatividade que podem ser corroborados por meio de teorias desenvolvidas pelos estudiosos apontados, bem como pelas características étnicas de cada localidade.

Todavia, revela-se que a linguagem é uma prática social a qual retrata as relações de poder (RAFFESTIN, 1993). Porém, percebe-se que um texto ao ser transmitido, carrega consigo uma mensagem ideológica e proposicional, a qual pode passar despercebida por um leitor iniciante. Assim, destaca-se a importância da transversalidade da Educação Ambiental no ensino das disciplinas tradicionais, afinal, todo texto possui um público e um propósito, e cabe aos professores possibilitarem instrumentos de fundamentação e interpretação textual (seja oral ou escrito) a fim de formar cidadãos críticos e não influenciáveis por determinadas posturas ideológicas (CAMARGO E SOUZA, 2017).

É interessante que o trabalho com a Educação Ambiental torne possível uma exploração de distintos gêneros textuais, levando-se em consideração um conjunto de parâmetros essenciais, tais como público-alvo, lugar social do emissor/receptor - os quais podem ser os povos indígenas presentes nas escolas -, objetivo comunicativo e temática abordada. Por isso, durante a pesquisa de campo foi proposta, como uma das atividades a serem produzidas pelos(as) professores(as) das escolas Kadiwéu e Terena, que identificassem, em revistas e jornais disponibilizados, imagens que retratassem circunstâncias para se desenvolver a Educação Ambiental em sala de aula.

Caso não encontrassem imagens que lhes chamassem a atenção, poderiam desenhar e/ou também produzir um poema, haja vista haver mais professores indígenas com formação em linguagens. Assim, poderiam apresentar uma mensagem e/ou forma de contextualizar nas suas disciplinas a Educação Ambiental. Para este artigo, foram escolhidas duas produções, com destaque para: a) escritas na língua materna; b) representação de natureza viva e morta; c) industrialização a partir da extração de recursos naturais; e d) explicação na língua portuguesa, conforme figuras 1 e 2 a seguir: 


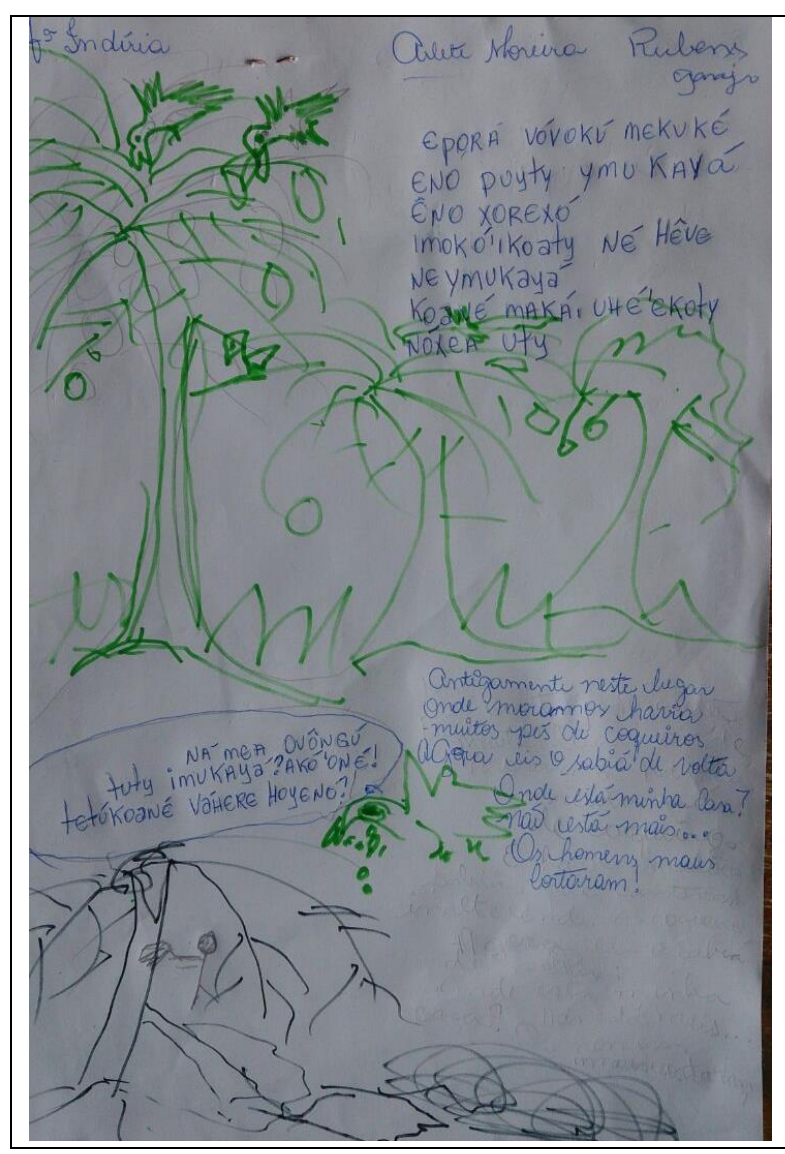

Figura 1: Representação produzida por professora Terena sobre Educação Ambiental.

Fonte: Souza, 2017.

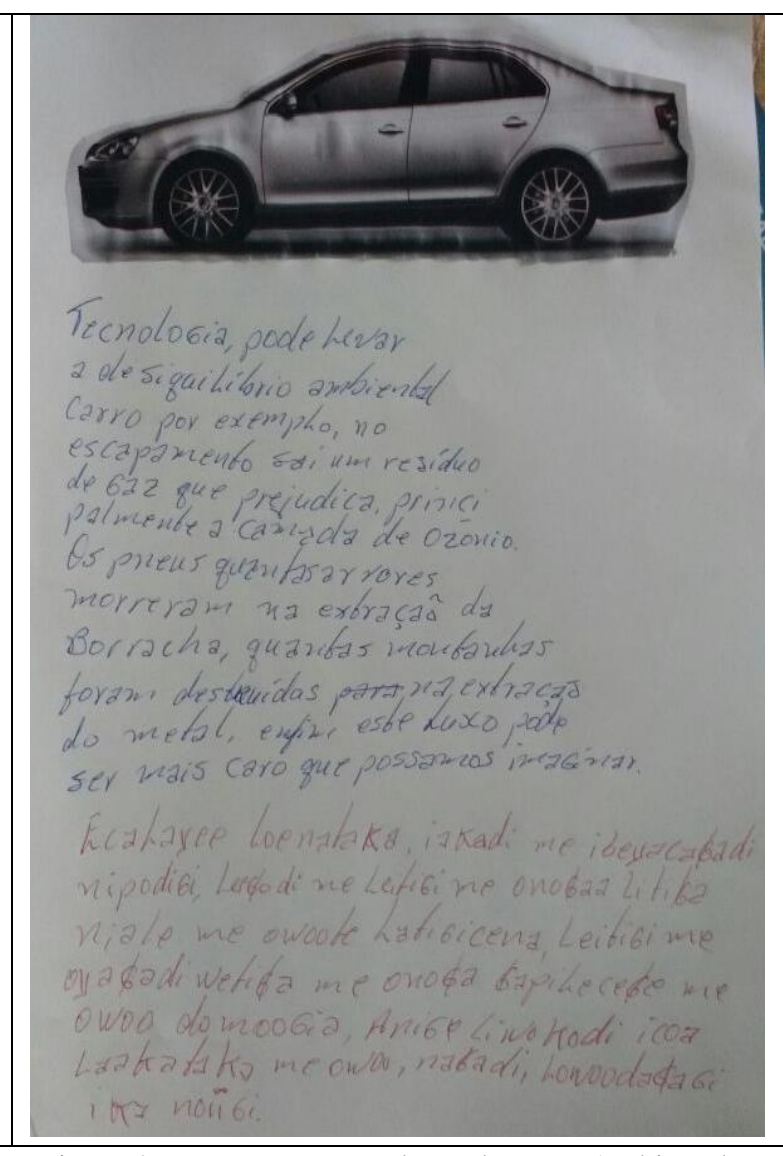

Figura 2: Representação sobre Educação Ambiental por professor Kadiwéu.

Fonte: Souza, 2017

Agora se descreve cada uma das figuras. A figura 1 foi produzida por uma professora da etnia Terena, graduada em letras/literatura pela UFMS, a qual expressou a possibilidade de trabalhar a Educação Ambiental na escola a partir do desenvolvimento de poema. A professora Terena, na figura 1, retrata a partir da utilização de cores, verde e preta, respectivamente, representando vida e destruição da natureza. Pela formação, utiliza-se da expressão poética como forma de reflexão sobre o quanto a natureza, no espaço vivido, vem sendo destruída pelos não-indígenas (identificados no trecho como "homens maus").

Enquanto a figura 2 foi produzida por um professor da etnia Kadiwéu, graduado em ciências sociais pela UFMS $^{7}$, que expressou a sociedade do consumo e a presença das tecnologias a partir da extração desordenada dos recursos naturais no processo de metamorfização da natureza, desdobrando-se em "desequilíbrio ambiental”, pois "é inegável que a cultura se transformou em algum gênero de mercadoria" (HARVEY, 2005, p.221). Isso foi bem exemplificado na figura 2, caracterizada por um veículo que emana poluentes na atmosfera.

Contudo, em ambas as figuras, evidenciam-se as territorialidades de representações sociais numa possibilidade didática, em que há a valorização, primeiramente das línguas maternas e, em seguida, uma abertura para a prática e reflexão, sobre como é percebida a Educação Ambiental pelos professores indígenas, em suas diversas áreas do conhecimento.

\footnotetext{
${ }^{7}$ Neste ano de 2018, este professor ingressou no Programa de Pós-Graduação em Antropologia na UFMS.
} 
Porém, a partir do momento em que o(a) aluno(a)/professor(a) indígena pode se expressar em sua língua materna e depois em língua portuguesa, constata-se que há uma maior fluidez de troca de saberes e valorizações culturais, as quais revelam maneiras de ser, pensar e agir. Assim, percebe-se que a Educação Ambiental caminha para a compreensão de ser um elemento desta fronteira etnocultural, a partir da apreensão de como as relações sociedade-natureza acontecem a partir desses saberes tradicionais.

Contudo, a conservação da natureza, nas práticas de Educação Ambiental, torna-se conflitante pela dicotomia entre os saberes tradicional e científico-moderno. Segundo Diegues (2008, p.71):

Configura-se, nesse caso, o confronto de dois saberes: o tradicional e o científicomoderno. De um lado, está o saber acumulado das populações tradicionais sobre os ciclos naturais, a reprodução e migração da fauna, a influência da lua nas atividades de corte da madeira, da pesca, sobre os sistemas de manejo dos recursos naturais, as proibições do exercício de atividades em certas áreas ou períodos do ano, tendo em vista a conservação das espécies. De outro lado, está o conhecimento científico, oriundo das ciências naturais que não apenas desconhece, mas despreza o conhecimento tradicionalmente acumulado. Em lugar da etnociência, instala-se o poder da ciência moderna, com seus modelos ecossistêmicos, com a administração "moderna" dos recursos naturais, com a noção de capacidade de suporte baseada em informações científicas (na maioria das vezes, insuficientes).

Nesse contexto, Morin (2000, p.20) explicou que "o conhecimento não é um espelho das coisas ou do mundo externo", isso consubstancia a importância da valorização de conhecer e aprender com estes mentores (povos indígenas) dos saberes tradicionais, e assim visualizar uma nova ótica de apropriação e uso da natureza.

Destarte, para que a transformação e o aprendizado ocorram, a escola cumpre papel destacado na formação dos cidadãos para uma vida saudável, na medida em que o grau de escolaridade tem associação comprovada com o nível de saúde dos indivíduos e grupos populacionais. Portanto, a formação do(a) aluno(a) para o exercício da cidadania compreende a motivação e a capacitação para o autocuidado, assim como a compreensão de seus limites para com o uso dos recursos naturais.

\section{CONSIDERAÇÕES FINAIS}

O presente artigo elegeu como objeto de estudo duas unidades de ensino, situadas geograficamente em locais e etnias distintas, com o objetivo de compreender a interface entre Kadiwéu e Terena quanto à(s) territorialidade(s) de representação(ões) social(is) sobre educação ambiental na Região do Pantanal Sul. A partir deste objetivo, reportam-se a Souza e Martins (2010, p.2), quando explicam que "[...] a dinâmica das relações entre indígenas e nãoindígenas se expressam como territorialidades e conflitos, afetando as comunidades constituídas ou em formação".

Nesse contexto, foi realizada uma compilação de dados teóricos os quais abordavam a temática em questão (Educação Ambiental). Desse modo, na primeira escola, constatou-se que os professores indígenas demonstraram interesse em compreender a necessidade de desenvolver práticas geo-pedagógicas voltadas para Educação Ambiental, a partir do melhor entendimento e devida formação para aplicarem em sala de aula. 
Inclusive, durante a pesquisa de campo, na primeira escola, constatou-se que os professores indígenas Kadiwéu são, predominantemente, do gênero masculino. Isso é algo incomum nos campos da licenciatura, sendo que nessa escola há apenas a presença de uma mulher, a qual auxilia no cuidado com as crianças menores (como se fosse uma inspetora de alunos). Ela cursa o Ensino Médio, porém se interessa pela atuação escolar como professora.

Quanto à existência da fronteira etnocultural, esta pôde ser comprovada pelo contato entre professores indígenas e não-indígenas os quais, incialmente, revelaram certa estranheza (MARTINS, 2009), frente ao diálogo sobre práticas de ensino abordadas, já que Souza e Martins (2010, p.9) afirmam:

[...] intui-se que a fronteira etnocultural se manifesta a partir do contato interétnico, da relação com o outro, com o diferente, entre indígenas e não-indígenas. As territorialidades evidenciam e caracterizam tais relações, tanto quanto os modos de vida observados no cotidiano.

$\mathrm{Na}$ segunda escola, a receptividade foi maior, observou-se que os professores indígenas demonstraram também significativos interesses em trocar saberes quanto ao desenvolvimento de práticas pedagógicas voltadas para Educação Ambiental, inclusive convidando alunos e pais destes para participarem da capacitação geo-pedagógica desenvolvida.

Entretanto, observou-se que a fronteira etnocultural pôde ser substancialmente comprovada tanto pela interação entre professores(as) indígenas e não indígenas, quanto pelo diálogo entre as distintas etnias presentes (não indígenas, Kadiwéu e Xavante) em uma mesma sala de aula - diferentemente da primeira escola que recebe apenas alunos(as) da etnia Kadiwéu - como foi possível identificar.

Por conseguinte, mediante a pesquisa de campo, tornou-se possível promover troca de saberes relativos à Educação Ambiental, assim como observar e comprovar a existência da fronteira etnocultural, a qual, nesse caso específico, concretizou-se por meio da interação e integração de indivíduos de diferentes etnias e culturas.

\section{Referências}

BOURDIEU, P. O poder simbólico. Rio de Janeiro: Bertrand Brasil, 2010. 322p.

CAMARGO, B. M. G. de; SOUZA, E. P. de. O ensino de educação ambiental em linguagens a partir dos saberes tradicionais dos povos indígenas da região do Pantanal Sul: Fronteiras Etnoculturais. In: VI Reunião de Antropologia de Mato Grosso do Sul. Povos tradicionais na contemporaneidade: cosmologias e territórios. Anais. UFMS, Campo Grande, 2017.

CHIZZOTTI, A. Pesquisa qualitativa em ciências humanas e sociais. 2. ed. Petrópolis, RJ: Vozes, 2008.

. Augusto Comte: reorganizar a sociedade. São Paulo: Editora Escala

(Coleção Grandes Obras do Pensamento Universal - 18).

DIEGUES, A. C. S. O mito moderno da natureza intocada. $6^{\text {a }}$ ed. São Paulo: HUCITEC, 2008. 
DUPAS, G. Meio ambiente e crescimento econômico: tensões estruturais. São Paulo: Editora UNESP, 2008.

GARZONI, E. de C.; PELLIN, A. A educação ambiental como ferramenta de mobilização social no processo de implementação do Corredor de Biodiversidade Miranda - Serra da Bodoquena (Mato Grosso do Sul, Brasil). INGEPRO. Inovação, Gestão e Produção. Junho de 2010, vol. 02, no.06 ISSN 1984-6193.

GUERRA, V. M. L; ENEDINO, W. C.; NOLASCO, E. C. Estudos de Linguagens: Diversidade e ensino. São Carlos: Pedro \& João Editores, 2012.

HARVEY, D. A produção capitalista do espaço. São Paulo: Annablume, 2005.

HOLZER, W. Uma discussão fenomenológica sobre os conceitos de paisagem e lugar, território e meio ambiente. Território, 1997, 2(3), 77-85.

JODELET, D. Les reprèsentations sociales. Paris: Presses Universitaires de France, 1989.

LACEY, H. Valores e atividade científica. São Paulo: Discurso Editorial, 1998.

LEFF, E. Epistemologia ambiental. $4^{\text {a }}$ ed. São Paulo: Cortez, 2006.

MACHADO, L. O. Limites, Fronteiras e Redes. In: STROHAECKER, T. M.; DAMIANI, A.; SCHAFFER, N. O.; BAUTH, N.; DUTRA, V. S. (org.). Fronteiras e Espaço Global. Porto Alegre: AGB, 1998. p.41-49.

MARTINS, J. de S. Fronteira: a degradação do Outro nos confins do humano. São Paulo: Contexto, 2009.

MORIN, E. Os sete saberes necessários à educação do futuro. $2^{\mathrm{a}}$ ed. São Paulo: Cortez; Brasília/DF: UNESCO, 2000.

MOSCOVICI, S. A representação social da psicanálise. Tradução de Cabral. Rio de Janeiro: Zahar, 1978.

NOGUEIRA, R. J. B. Fronteira: espaço de referência identitária? Ateliê Geográfico, Goiânia, v.1, n. 2, p. 27-41, dez. 2007.

POUTIGNAT, P.; STREIFF-FERNART, J. Teorias da etnicidade. Seguido de grupos étnicos e suas fronteiras de Fredrik Barth. São Paulo: UNESP, 1998.

RAFFESTIN, C. Por uma Geografia do poder. São Paulo: Editora Ática, 1993.

SACK, R. D. Human territoriality: its theory and history. Cambridge: Cambridge University Press, 1986.

SALVI, R. F.; BATISTA, I. L. A análise dos valores na filosofia da ciência e na educação científica. In: VI ENPEC - Encontro Nacional de Pesquisa em Educação em Ciências. Florianópolis: Floriprint, 2007. v. 1. p. 1-12. 
SÊGA, R. A. O Conceito de Representação Social nas Obras de Denise Jodelet e Serge Moscovici. Anos 90. Porto Alegre, n. 13, julho. 2000.

SILVA, L. E.; MENEZES, E. M. Metodologia da pesquisa e elaboração de dissertação. 4 ed. Florianópolis: UFSC, 2005.

SOUZA, E. P. de. Territorialidades e conflitos entre o Distrito de Taunay e as aldeias circunvizinhas: Fronteiras Etnoculturais. Dissertação (Mestrado em Estudos Fronteiriços) Universidade Federal do Mato Grosso do Sul, Campus do Pantanal: Corumbá - MS, 2012, p. 91.

SOUZA, E. P; MARTINS, S. R. O. A Fronteira Etnocultural entre territorialidades indígenas e não indígenas no Distrito de Taunay. Anais XVI Encontro Nacional de Geógrafos. Porto Alegre: 2010.

SOUZA, E. P.; RAMOS, M. B; MARTINS, S. R. O. Estudo preliminar de impactos ambientais no Parque Natural Municipal da Lagoa Comprida. In: XVI Encontro Sul-MatoGrossense de Geógrafos / VI Encontro Regional de Geografia, 2008, Dourados. Anais. Dourados: AGB - Seção Local Dourados, 2008. v. 1. p. 001-008.

TURNER, F. J. History, Frontier and Section: three essays. New Mexico: University of New Mexico, 1993. 